\section{Not your normal redleg}

\section{To the editor:}

I read with interest the "What's your diagnosis? Limb discoloration on a depressed tree frog (Hyla cinerea)" in Lab Animal, Vol. 34, No. 3. As a superintendent of herpetology at the Bronx Zoo in New York, and later as curator of animals at the Central Park Zoo, I often had occasion to observe somewhat mysterious and acute onslaughts of remarkable diseases. Thus, I was eager to apply my past expertise to the challenge at hand.

There are some obvious precursors to a diagnosis. First, the frog is missing at least one of its five toes. Second, it is deep green and the view lacks either white spots on the face under the eye, or a white stripe along the jaws that usually extends well onto the side of the body, suggesting that the frog depicted is not a Hyla cinerea, which is commonly called the green tree frog. Also, the American tree frog is the name usually applied to Hyla avivoca, the bird-voiced tree frog, or Osteopilus septentrionalis, the Cuban tree frog.

Regarding the diagnosis, one can clearly see that the animal has a red swollen leg. Moreover, having a single red swollen leg, that incidentally lacks some of its toes, suggests to me a case originating by what us old supervisors would call 'keeperitis'. Redleg bacterial infections are usually visible as small capillary hemorrhages and inflammation that shows on the inside of both hind legs, resulting from a systemic infection. Most often, small frogs are dead long before any localized necrosis sets in. A single badly affected leg does not ring true. Rather, upon seeing such a presentation, I would first ask the keeper of the frog if he or she might have inadvertently crushed the leg as the frog attempted to leap from the tank, or secondly, if the frog had been marked for identification by clipping off one or more toes on the front foot in a numerical order. In either case, the trauma could have led to a localized infection, swelling, reddening, and necrosis of that one foot. Further, systemic redleg, regardless of the actual bacteria involved, is almost always fatal if not treated systemically. That the frog was treated locally and survived for weeks takes me back to the localized trauma and subsequent infection scenario.

\section{Peter Brazaitis, MS}

Harwinton, CT.

email:croc1@99main.com

\section{Mayer replies:}

A picture taken during the follow up examination shows the frog from a different angle, and supports our identification, as you can clearly see the characteristic white stripe (Fig. 1).

Concerning classical redleg, I agree with Brazaitis' points. This particular case is not a textbook presentation of redleg syndrome. I submitted this case to the magazine because the lesion was so clearly visible and identifiable for even the novice observer. Figure 2 shows an amphibian patient displaying typical signs of redleg. For the untrained eye it would be a bit more difficult to diagnose the dilated vessels and reddish discoloration of the ventrum as something abnormal.

Since I work at a veterinary school, I always try to teach my students interesting cases. I thought that this case, although not typical redleg, would draw attention to my favorite animals, the amphibians, and demonstrate that it is quite possible to practice good medicine on such patients, instead of declaring "there is nothing you can do about it."

During my appointment with the caretaker I took the time to ask very specific questions about the husbandry, since I suspected a traumatic incident as a primary lesion that progressed into the septic event.

Again, I agree with Brazaitis' assessment of the case. My primary goal with this article was to introduce the readership to the fascinating world of amphibian medicine, and to educate them about the etiology of the term 'redleg'.

\section{Jörg Mayer, Dr. Med Vet., MSc}

Tufts University School of Veterinary Medicine, Grafton, MA. email:joerg.mayer@tufts.edu

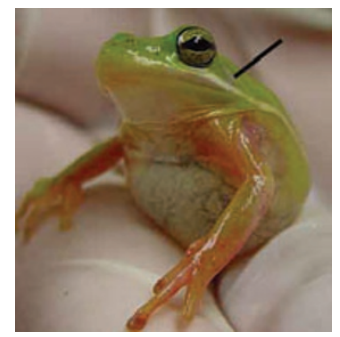

FIGURE 1 | The characteristic white stripe along the jaw (arrow) of a green tree frog (Hyla cinerea).

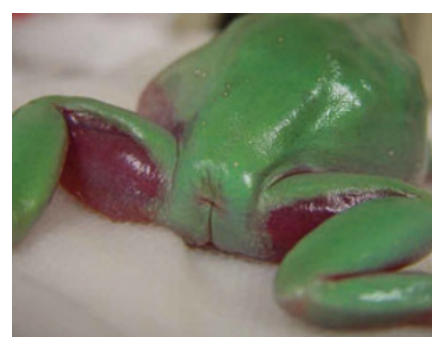

FIGURE 2 | A frog displaying the typical signs of redleg.

\section{Column Editor replies:}

Knowing the natural history of the species and genus of frog is clinically important for husbandry and nutrition, but the usefulness of identification down to sub-family or family really depends on the species. Brazaitis points out that most species can be kept under similar conditions: $\operatorname{cool}\left(65-75^{\circ} \mathrm{F}\right)$ and humid, with available open water, a place to hide, nothing that creates a fungal condition in the tank, but not together with animals that have particularly toxic skin secretions.

For the veterinarian in need of a good frog identification book, Mayer recommends Reptiles, Amphibians, and Invertebrates: An Identification and Care Guide by Bartlett et al. (Barron's Educational Series, 2001).

\section{Thomas M. Donnelly, DVM}

email:tom@tomvet.com 